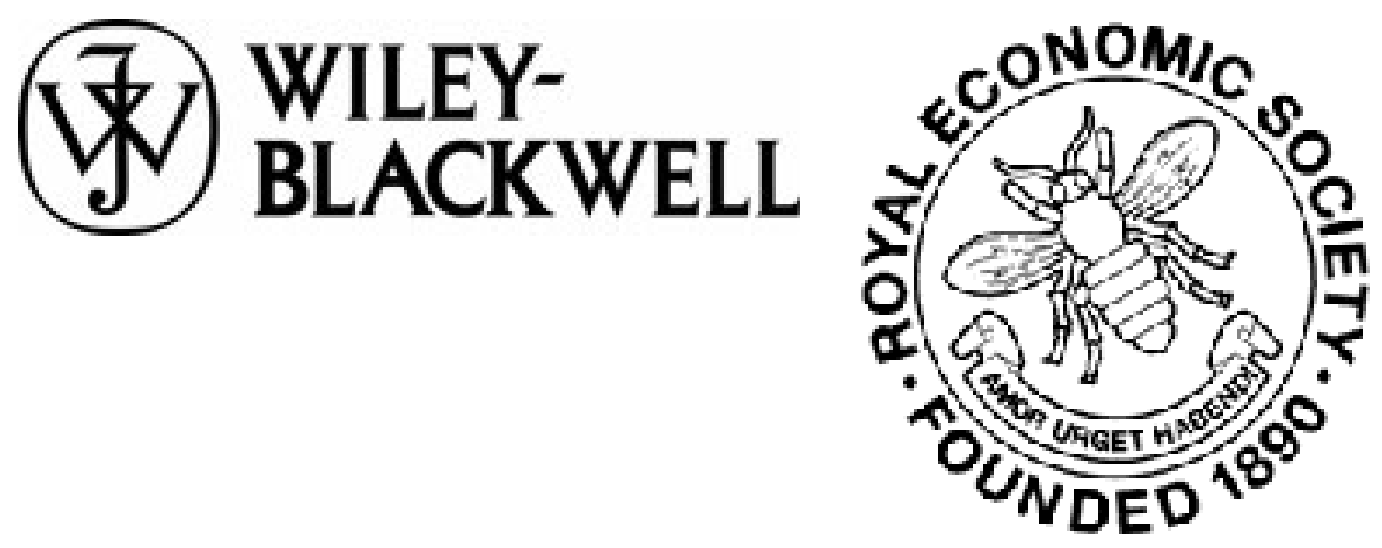

Futures Versus Share Contracting as Means of Diversifying Output Risk Author(s): David Hirshleifer and Avanidhar Subrahmanyam

Source: The Economic Journal, Vol. 103, No. 418 (May, 1993), pp. 620-638

Published by: Blackwell Publishing for the Royal Economic Society

Stable URL: http://www.jstor.org/stable/2234535

Accessed: 18/02/2011 17:24

Your use of the JSTOR archive indicates your acceptance of JSTOR's Terms and Conditions of Use, available at http://www.jstor.org/page/info/about/policies/terms.jsp. JSTOR's Terms and Conditions of Use provides, in part, that unless you have obtained prior permission, you may not download an entire issue of a journal or multiple copies of articles, and you may use content in the JSTOR archive only for your personal, non-commercial use.

Please contact the publisher regarding any further use of this work. Publisher contact information may be obtained at http://www.jstor.org/action/showPublisher?publisherCode=black.

Each copy of any part of a JSTOR transmission must contain the same copyright notice that appears on the screen or printed page of such transmission.

JSTOR is a not-for-profit service that helps scholars, researchers, and students discover, use, and build upon a wide range of content in a trusted digital archive. We use information technology and tools to increase productivity and facilitate new forms of scholarship. For more information about JSTOR, please contact support@jstor.org.

Blackwell Publishing and Royal Economic Society are collaborating with JSTOR to digitize, preserve and extend access to The Economic Journal. 
The Economic Journal, ro3 (May), 620-638. (C) Royal Economic Society r993. Published by Blackwell

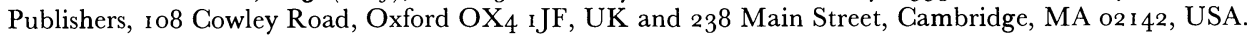

\section{FUTURES VERSUS SHARE CONTRACTING AS MEANS OF DIVERSIFYING OUTPUT RISK*}

\section{David Hirshleifer and Avanidhar Subrahmanyam}

Two means that commodity suppliers can use to reduce their exposure to risk are futures trading and share contracting. Futures contracts on a wide variety of commodities are actively traded in the United States and in other countries worldwide. In a share contract, the output of a plot of land is shared proportionately between the grower and another contractor at a pre-specified price. The share purchaser is typically a commodity processor who plays on using the commodity for future production. ${ }^{1}$ Share contracting for grains and cotton is extensive in the United States (see Paul et al. (1976), and Miller (I986)). In describing the share contracting institutions for sugar, coffee, and cocoa in Latin America and Africa, Goldsmith (1985) refers to share purchases from multiple growers as the 'core-satellite model'. In these arrangements a multinational company typically contracts with many small growers in less developed countries.

It might appear at first that futures trading and share contracting would be substitute means of sharing risk, suggesting that the introduction of a futures market would reduce the need for share contracting. If so, then an intriguing issue is why share contracts remain popular even for commodities for which futures markets have been established successfully, such as grains, sugar, coffee, cotton, and cocoa. This paper provides an explanation for the coexistence of futures trading and share contracting by demonstrating that these will frequently be complementary means of transferring risk.

The starting point of our analysis is that a grower's harvest depends not only on marketwide factors such as general weather conditions, but on factors specific to the grower or his locality. When harvests are imperfectly correlated, ${ }^{2}$ there is a benefit to diversifying the specific or 'idiosyncratic' risks by purchasing output shares from a number of different growers. ${ }^{3}$ Indeed,

* We would like to thank D. Diamond and R. Roll for stimulating our interest in this topic; two anonymous referees, the editor John Hey, F. Allen, M. Brennan, V. France, S. Lippman, D. McCloskey, D. Newbery, S. Titman, H. Zink, participants at the UCLA finance seminar and at the 1990 European Finance Association Meetings for insightful comments and suggestions, and the Center for International Business and Economic Research at UCLA for financial support.

1 We distinguish share contracting with intermediate commodity producers from sharecropping, a form of land rental in which the grower commits to deliver a fraction of his output to the owner of the land. Sharecropping is discussed later in the following paragraph.

${ }^{2}$ For corn and wheat, local conditions lead to quite diverse distributions of crop yields. Johnson (1945) found squared correlations between county or state yields to national United States yields of $0 \cdot 05$ to $0 \cdot 7$ I. Correlations among individual growers would of course be lower.

${ }^{3}$ Diversification of output risks has been suggested as the explanation for the open fields system of agriculture typical of England up to the seventeenth to eighteenth centuries. According to McCloskey (I976) 'the typical villagers of the Midlands of England... held some 20 acres in the fields of his village in twenty or so separate locations'. 
Newbery and Stiglitz ( $198 \mathrm{I} ;$ pp. 54-5) suggested that such risk-pooling is one reason why renewable resource industries with many small harvesters are usually served by a few processors, whose much larger size does not appear to be explained by technological considerations alone.

While the benefits of multiple share contracting depend on imperfect correlations among the stochastic outputs of different growers, futures trading is useful for hedging common risks, those correlated with the price of the commodity. When multiple share contracting is used to diversify the idiosyncratic risk components, it has the drawback of loading excessive common risk on the purchaser. Insofar as a futures market is available to remove the common risk component, the advantage of share contracting among multiple growers to diversify quantity risk frequently increases. ${ }^{4}$

The foregoing discussion indicates that our model is designed to address the behaviour of producers who are concerned with both the expected value and the variability of their revenues. ${ }^{5}$ Most growers (due to moral hazard, adverse selection, or trading costs) do not issue equity and so have reason to be concerned with revenue variability. ${ }^{6,7}$ The role of diversifying the output risk of producers can be performed by intermediate agricultural producers (storers and processors), ranging from large corporations to small rural grain elevators, who often engage in share contracting with small producers. Therefore, some processors may be more tolerant of risk than growers (but see footnote 5 above). Growers' cooperatives (which usually act as intermediate processors of grains - see Roy (I963)) may also provide share contracts to their members so as to reduce output risks. (Kimball ( 1988 ) provides a model in which cooperatives pool idiosyncratic risks across growers.)

As distinct from the share contracts with intermediate processors discussed above, our analysis can also be applied to sharecropping, contracts in which growers commit to deliver a fixed fraction of their output to a landlord. As a form of land rental, such contracts are a common arrangement in several countries. Most of the literature on sharecropping focuses on moral hazard (due to the effect upon incentives of growers) or on self-selection among different types of growers (e.g. Cheung ( I 969), Stiglitz (1974), Newbery and Stiglitz (1979), Allen ( I985), Braverman and Stiglitz ( I986); Newbery (1976)

\footnotetext{
${ }^{4}$ Share contracting arrangements are common between small growers in less developed countries (LDC's) and large multinational corporations. Generally, LDC growers will not have as ready access to futures markets as those in advanced economies. The complementarity of futures trading with share contracting becomes stronger when only processors trade futures than when processors and growers have symmetric access to futures markets, because the risk premia that growers are willing to pay to remove part of their revenue risk are larger when they cannot trade futures.

${ }^{5}$ In contrast, in models with perfectly diversified individuals such as the Capital Asset Pricing Model, producers are concerned not with variability per se but with the covariance of their cashflows with the stock market of traded securities. Some of the major United States storage and processing firms, such as Cargill, Continental Grain and Dreyfus are privately held, so that their undiversified owners may have incentives to reduce residual (non-stock-market) risk. Diamond and Verrecchia (1982) describe in an agency framework why managers even of publicly held firms would seek to avoid residual risk.

6 The great bulk of United States grain output is accounted for by small non-corporate growers.

7 Possible reasons for the greater frequency of share contracting than the issuance of publicly held equity could be that the contractors are better positioned to observe weather and local factors influencing output, limiting adverse selection and moral hazard, or that the small optimal scale of production does not justify the cost of going public.
}

(C) Royal Economic Society 1993 
focuses on risk sharing through sharecropping versus labour contracts). These papers do not, however, examine the interaction of sharecropping with futures markets, which is our topic.

In the next section we describe the basic economic setting. In Section II, we examine the advantage to share diversification in the absence of a futures market. Section III describes the conditions under which futures trading promotes share diversification. Section IV makes the share size endogenous, and Section V concludes the paper.

\section{THE EGONOMIG SETTING}

We examine a commodity market that is competitive and subject to independent supply and demand shocks. In order to capture in a simple way the notion that a producer's output depends partly on common influences (e.g. rain versus shine) and partly on influences specific to the producer or locality, we assume a linear form for the joint distribution of producers' outputs. Grower $i$ 's output $\tilde{q}_{i}$ satisfies

$$
\begin{gathered}
\tilde{q}_{i}=\beta_{i} \tilde{q}+\tilde{\epsilon}_{i}, \quad \mathrm{E}\left(\tilde{\epsilon}_{i} \mid q\right)=\mathrm{o}, \quad i=\mathrm{I}, \ldots, N, \\
\sum_{i=1}^{N} \tilde{\epsilon}_{i} \equiv \mathrm{o}, \quad \frac{\mathrm{I}}{N} \sum_{i=1}^{N} \beta_{i}=\mathrm{I} .
\end{gathered}
$$

Here $\beta_{i}$ is a constant, $\tilde{q}$ may be viewed as a common 'factor' influencing the different growers' outputs, and $\tilde{\epsilon}_{i}$ is grower-specific, or idiosyncratic variability. By summing the individual outputs $\tilde{q}_{i}$ over producers $i$, we see that $\tilde{Q} \equiv N \tilde{q}=$ $\sum \tilde{q}_{i}$ is aggregate output, so that $\tilde{q}$ is the output of an average grower. The coefficient $\beta_{i}$ represents the sensitivity of the output to common environmental influences. $^{8}$ The best way to view the condition in (I) that the idiosyncratic components sum across growers to zero is that $\tilde{\epsilon}_{i}$ measures the level of a grower's output in comparative terms, after extracting all systematic fluctuations. For example, if in some states of nature the $\epsilon_{i}$ 's had a positive sum, this would indicate high output for all growers; however, such systematic fluctuations are reflected in $\tilde{q}$ rather than in the idiosyncratic term $\epsilon_{i}{ }^{9}$

Production costs are assumed to be zero, so that there is no distinction between crop-share and equity contracts. (The analysis could easily be extended to allow for a stochastic harvesting cost.) Let $\widetilde{P}$ be the spot price for the commodity. Then the $i$ th grower's revenue is $\beta_{i} \tilde{P} \tilde{q}+\tilde{P} \tilde{\epsilon}_{i}$. The two components of this sum may be termed systematic risk, and idiosyncratic risk respectively. The systematic risk term $\beta_{i} \tilde{P} \tilde{q}$ is the revenue derived from the component of output that varies proportionately with aggregate output. The

\footnotetext{
8 The assumptions in ( $\mathrm{I}$ ) are similar to the requirements on security returns in Ross' (1978) work on separating distributions. An example satisfying this structure is a set of multivariate normally distributed outputs, where (I) may be interpreted as a 'market model' regression of $\tilde{q}_{i}$ on $\tilde{q}$.

${ }^{9}$ Note that by transforming variables, an output distribution in which the 'idiosyncratic' components sum to a random number can be converted into the form given here. The distribution is therefore less restrictive than initial appearances may suggest. Consider the representation $q_{i}=\beta_{i} q_{1}+\eta_{i}$, where the $\eta_{i}$ 's sum is stochastic. Then, by defining $q \equiv\left(\sum_{i-1}^{N} \eta_{i} / \Sigma_{i-1}^{N} \beta_{i}\right)+q_{1}$ and $\epsilon_{i} \equiv \eta_{i}-\left(\beta_{i} / \Sigma_{i=1}^{N} \beta_{i}\right) \Sigma_{i-1}^{N} \eta_{i}$, one obtains the output distribution (I).
}

(C) Royal Economic Society I993 
idiosyncratic risk term $\tilde{P} \tilde{\epsilon}_{i}$ is revenue derived from the component of output that is conditionally independent of aggregate output. ${ }^{10}$

Henceforth, we suppress all tildes unless essential for clarity. Let $w_{i} \equiv P \epsilon_{i}$, the idiosyncratic term and let $Z \equiv P q$, the systematic variable. Now $\operatorname{cov}\left(Z, w_{i}\right)=0$, as the equilibrium spot price $P$ is a function of only $q$ and the independent demand shock, so that $\epsilon_{i}$ is conditionally independent of $P$ (as well as $q) .{ }^{11}$ Since the $\epsilon_{i}$ 's sum to zero, (I) imposes negative dependence on the $\epsilon_{i}$ 's (i.e. pairwise covariances are typically negative). For example, if the $\epsilon_{i}$ 's are identically and symmetrically distributed,

$$
\mathrm{o}=\operatorname{cov}\left(\sum \epsilon_{i}, \Sigma \epsilon_{i}\right)=\Sigma \sigma^{2}+2 \sum_{i} \sum_{j<i} \sigma_{i j}
$$

where $\sigma^{2}$ is the common variance and $\sigma_{i j}$ is the common covariance, so that

$$
\sigma_{i j}=-\sigma^{2} /(N-\mathrm{I})<\mathrm{o} .
$$

Furthermore, negatively correlated $\epsilon_{i}$ 's typically imply negatively correlated $w_{i}$ 's. ${ }^{12}$

We examine a scenario in which growers can sell fractional shares of their crops in advance to another firm (a processor). We assume that the growers and the processor are each endowed with a non-random initial wealth level $W .^{13}$ Letting $\mathrm{E}$ be the expectation operator and $C$ be consumption, we assume the common mean-variance preferences for all individuals

$$
v[\mathrm{E}(C), \operatorname{var}(C)]=\mathrm{E}(C)-\frac{A}{2} \operatorname{var}(C) .
$$

This is a monotonic transformation of a Neumann-Morgenstern expected utility function under the assumptions of constant absolute risk averse (exponential) utility and normality of consumption. ${ }^{14}$ This specification of preferences causes risk premia to be proportional to variances and to absolute risk aversion, and thereby facilitates considerably our analysis of gains to particular risk sharing arrangements. The parameter $A$ may be viewed as a measure of absolute risk aversion. In Section IV we examine the effect of reducing a processor's risk aversion relative to that of growers.

10 One can generalise the analysis to allow for a pure price risk term in the expression for grower revenues, so that output takes the form $q_{i}=\alpha_{i}+\beta_{i} q+\epsilon_{i}$, with $P \alpha_{i}$ then representing pure price risk. We set $\alpha_{i}$ equal to its 'typical' level of zero, $i=\mathrm{I}, \ldots, N$, so that outputs are proportional in expectation. It is not hard to extend the analysis to allow for differing $\alpha_{i}$ 's; deţails are available from the authors. This entails $\beta_{1}$, $\beta_{2}>0$ (and restriction of the support of $\epsilon_{1}$ and $\epsilon_{2}$ ) to avoid the absurdity of negative expected output.

$11 \mathrm{Cov}\left(P q, P \epsilon_{i}\right)=\mathrm{E}\left(P^{2} q \epsilon_{i}\right)-[\mathrm{E}(P q)]\left[\mathrm{E}\left(P \epsilon_{i}\right)\right]$. But for any function $F$ of $P$ and $q, \mathrm{E}\left[F(P, q) \epsilon_{i}\right]=$ $\mathrm{E}_{P, q}\left[F(P, q) \mathrm{E}_{\epsilon_{i} \mid P, q}\left(\epsilon_{i}\right)\right]=0$, so the covariance above is zero.

${ }^{12}$ This follows immediately if the $\epsilon_{i}$ 's are independent, rather than just conditionally independent of $q$.) More generally, this follows under the mild condition that $\operatorname{sign}\left[\operatorname{cov}\left(\epsilon_{i}, \epsilon_{j} \mid P\right)\right]$ does not vary with $P$, so that the tendency for errors to move together or in opposition does not reverse over different market price outcomes. Proof: $\operatorname{cov}\left(w_{i}, w_{j}\right)=\mathrm{E}\left(w_{i} w_{j}\right)=\mathrm{E}_{P}\left[P^{2} \mathrm{E}_{\epsilon_{i}, \epsilon_{j} \mid P}\left(\epsilon_{i} \epsilon_{j}\right)\right]=\mathrm{E}_{P}\left[P^{2} \operatorname{cov}\left(\epsilon_{i}, \epsilon_{j} \mid P\right)\right]$

13 It is not difficult to generalise the analysis to the case in which processors are endowed with a stochastic revenue that covaries with growers' revenues; details are available from the authors. Hirshleifer (I 988) and Weller and Yano (1992) examine the determination of this covariance.

14 Newbery ( 1987 ) estimates the errors of the mean-variance approximation in commodity markets to be negligible for calculation of futures hedging positions and the benefits of risk reduction under reasonable parameter values.

(C) Royal Economic Society I993 
By assumption, the share contract here takes the form of a proportional sharing rule, i.e. shares of the total output are traded for a fixed cash payment, with equal percentage shares across growers. We do not attempt to solve for optimal sharing rules as arbitrary functions of the outcome. Braverman and Stiglitz (I986) provide a number of justifications for this approach, based on the prevalence of share contracts with standard provisions in actual commodity markets, the transaction costs associated with contingent contracts, and the possibility of commodity arbitrage between agents receiving non-linear contracts. In addition, we will argue that the availability of futures contracts reduces the need to resort to more elaborate arrangements.

\section{SHARE DIVERSIFIGATION WITHOUT A FUTURES MARKET}

In our model, the desirability of a share contracting arrangement is measured by the difference between the amount that share sellers are willing to pay to remove risk and the amount demanded by the share purchaser to bear additional risk. If the willingness to pay exceeds the reservation value, a mutually profitable transaction becomes possible.

We begin by exogenously constraining the size of the share purchase. Each grower, if he so chooses, may sell a crop share $s$ forward to a single buyer, and retain the remaining fraction $\mathrm{I}-s .{ }^{15}$ Subsection II. I summarises a basic result relating risk premia to preferences and payoff distributions. In Subsections II.2 and II.3, we examine the gains to share contracting in cases in which a processor contracts with two and many growers respectively.

Ideally, a highly risk averse grower might hedge by selling a substantial fraction of his output forward to several buyers. (Such a hedge must be adjusted by a long or short position taken to exploit any bias in the futures price as a predictor of the later spot price; see, e.g. Newbery and Stiglitz (I98I).) Alternatively, he may join a cooperative that divides profits among many growers. However, either alternative leads to an obvious incentive problem for a grower who retains only a small revenue share. In reality, growers typically sell shares to only one or a few buyers (e.g. USDA ( 1977)). Furthermore, when joint inputs from both processor and grower are required, a small share purchase may create a moral hazard problem on the part of the processor. ${ }^{16}$ Relatedly, there is a potential free-rider problem in monitoring amongst processors that could weaken the incentive of the grower. (Goldsmith (I985) notes that monitoring of growers' inputs by the processor is required in 'coresatellite' arrangements.) Finally, sales of small shares to many processors may be deterred by fixed transaction costs per contract. In Section IV the share size is determined endogenously as a function of transaction costs.

15 If the processor could costlessly issue shares in turn, then he would have an incentive to act as a financial intermediary between growers and outside investors. We assume that equity issuance is costly, and treat the share purchaser as a single individual.

16 Often, processors are required under the terms of share contracts to provide important inputs, such as crop-collection, machinery, fertiliser, and technical assistance (Goldsmith (1985), Glover (1987)). Glover lists some forms of shirking by processors (with citations of case studies), such as poor technical advice, and exploiting poor specification of quantities and dates for promised inputs.

(C) Royal Economic Society 1993 


\section{I. Some Basic Properties of Risk Premia}

Suppose that an individual with a mean-variance function $v(\cdot)$ is endowed with wealth $W+\tilde{x}+\tilde{y}$. The risk removal premium $\rho(\tilde{x} ; \tilde{y}, W)$ is the amount he would be willing to pay (as a deviation from the expected value) to have the gamble $\tilde{x}$ removed from his endowment, and the risk-acceptance premium $\theta(\tilde{x} ; \tilde{y}, W)$ is the amount demanded by an individual endowed with a wealth $W+\tilde{y}$ for bearing the gamble $\tilde{x}$, defined as

$$
\begin{aligned}
& \mathrm{E}[v(W+\tilde{y}+\tilde{x})]=\mathrm{E}\{v[W+\tilde{y}+\mathrm{E}(\tilde{x})-\rho(\tilde{x} ; \tilde{y}, W)]\}, \\
& \mathrm{E}[v(W+\tilde{y})]=\mathrm{E}\{v[W+\tilde{y}+\tilde{x}-\mathrm{E}(\tilde{x})+\theta(\tilde{x} ; \tilde{y}, W)]\} .
\end{aligned}
$$

By substituting the expected utility function (3) into (4) and (5), we obtain

$$
\rho(\tilde{x} ; \tilde{y}, W)=\theta(\tilde{x} ; \tilde{y}, W)=\frac{A}{2}[\operatorname{var}(\tilde{x}+\tilde{y})-\operatorname{var}(\tilde{y})] .
$$

Thus, in the case where agents possess mean-variance preferences, the removal and acceptance premia are equal and proportional to the absolute difference between the initial variance and the variance after removing/accepting the gamble $\tilde{x}$.

\section{II.2. Combining Two Output Shares}

We will determine conditions under which share contracting is profitable, i.e. growers are willing to pay risk premia to remove shares $s$ from each that are greater than the premium demanded by the processor to bear these combined gambles. To do so, we examine how variances, and therefore, risk premia, are affected by the share sales. Subtracting the acceptance from the removal premia then enables us to obtain conditions under which profitable diversification can occur. We stress that our concept of diversification involves combining imperfectly correlated gambles, rather than subdividing a fixed amount of wealth across an increasing number of gambles. Samuelson ( 1963 ) first pointed out this distinction between diversifying by 'averaging' versus adding multiple independent gambles, and that adding gambles was not necessarily desirable for a risk averse individual. Diamond's ( I 984) conditions on preferences describe when the diversification due to repeated added risks is preferable. These conditions are closely related to the Proper Risk Averse preferences of Pratt and Zeckhauser ( 1987). Also, Lippman and Mamer ( I 988) provide a general analysis of conditions in which adding many independent risks is desirable. Our analysis applies a tractable mean-variance framework. The assumption of mean-variance preferences with constant discounting for variance in expected utility (as in (3)) implies that individuals are precisely neutral with respect to combining independent gambles. Thus, the results offered here regarding the desirability of futures and share contracting do not derive primarily from preferences.

Let $V_{1}$ and $V_{2}$ be the variances of two growers' revenues. The sum of the maximum premia they would pay to remove share $s$ is $(A / 2)$ $\left[V_{1}-(\mathrm{I}-s)^{2} V_{1}\right]+(A / 2)\left[V_{2}-(\mathrm{I}-s)^{2} V_{2}\right]$, an amount proportional to the

(C) Royal Economic Society 1993 
growers' reductions in variance. Letting $V_{12}$ be the variance of the combined revenues from the two growers, the processor's acceptance premium is $(A / 2) s^{2} V_{12}$. Subtracting the acceptance premium from the removal premium and substituting the output distribution from (I) gives:

\section{Proposition I Share Diversification without Futures}

Under mean-variance preferences and the linear output factor structure (I) diversification by combining output shares is profitable if and only if

$$
\sigma_{Z}^{2}\left[\left(\beta_{1}^{2}+\beta_{2}^{2}\right) s(\mathrm{I}-s)-\beta_{1} \beta_{2} s^{2}\right]+s(\mathrm{I}-s)\left(\sigma_{w 1}^{2}+\sigma_{w 2}^{2}\right)-s^{2} \operatorname{cov}\left(w_{1}, w_{2}\right)>0 .
$$

The primary benefit from share contracting, diversification of idiosyncratic output risks, is reflected in the second and third terms of $(7)$, and tends to rise with the dispersion of these risks, as reflected in $\sigma_{w 1}$ and $\sigma_{w 2}$, and declines with $\operatorname{cov}\left(w_{1}, w_{2}\right)$ (a negative covariance being more favourable to diversification). The first term represents the cost of combining shares, i.e. the possibility of an excessive concentration of systematic risk on the processor. This is best illustrated by the case of equal systematic risk, $\beta_{1}=\beta_{2}$. In (7), the coefficient of $\sigma_{Z}^{2}$ then becomes $\beta^{2} s(2-3 s)$, so that for small purchases $(s \leqslant 2 / 3)$, systematic risk is spread more evenly between the growers and the processor, increasing the benefit to share contracting. If $s>2 / 3$, excessive systematic risk is loaded on the processor, reducing the benefit to share transacting. The special case $s=$ I can be viewed as lateral integration, that is, combining the revenues of two growers. The concentration of systematic risk is especially severe in this case. $^{17}$

When systematic risks are unequal, $\beta_{1} \neq \beta_{2}$, the gain to share contracting may be greater. For example, if $s=2 / 3$, the coefficient of $\sigma_{Z}^{2}$ becomes $2\left(\beta_{1}+\beta_{2}\right)^{2} /$ $9>0$, whereas with equal systematic risk, the gain was zero. The third term in (7) is positive when $\operatorname{cov}\left(w_{1}, w_{2}\right)<0$ (the typical case), indicating a further benefit to share contracting, diversification of idiosyncratic risk.

\section{II.3. Combining Many Output Shares}

We now examine the desirability of combining the shares of many rather than just two growers. Let $m$ be the number of growers from whom each processor buys shares, and let $\sigma_{i}$ be the variance of the idiosyncratic component of the revenue of grower $i$. For simplicity, let growers have a common systematic risk parameter $\beta$. By reasoning similar to that in the previous subsection, it is straightforward to derive the analog of Proposition I :

\section{Proposition 2 Share Diversification with Many Growers}

Share diversification by purchasing equal shares from $m$ growers with identically distributed outputs is profitable if and only if

$$
m \beta^{2} \sigma_{Z}^{2} s[2-(m+\mathrm{I}) s]+2 s(\mathrm{I}-s) \sum_{i=1}^{m} \sigma_{i}^{2}-2 s^{2} \sum_{i=1}^{m} \sum_{j<i} \operatorname{cov}\left(w_{i}, w_{j}\right)>0 .
$$

17 It is possible to extend the analysis of lateral integration to a more general family of preferences. If Diamond's (1984) conditions on preferences obtain, then lateral integration becomes more profitable than in the analysis above. (Details are available from the authors.)

(C) Royal Economic Society I 993 
The first term, due to systematic risk, is positive, favouring diversification so long as $2 /(m+\mathrm{I})>s$. For small $m$, the advantage to growers of removing part of their systematic risk outweighs the cost to the processor unless the share purchase is large. However, if the processor buys from many growers the cost of loading systematic risk on a single party becomes dominant, deterring share diversification. The second and third terms reflect the advantage of diversifying idiosyncratic risk. The second term is always non-negative, and the third tends to be non-negative, since the pairwise covariances are typically negative.

For commodities for which no futures market is available, an empirical implication of Proposition 2 is that multiple share contracting should be more extensive in localities whose outputs have low correlation with the market price, as these regions have relatively high idiosyncratic risk and low systematic risk.

\section{THE EFFEGT OF FUTURES TRADING}

Many small growers do not trade futures, possibly because of the setup costs of learning to use the futures market. If a larger processor is more prepared to do so, then there is an immediate benefit to forward contracting (a private arrangement to sell in advance either crop shares or a fixed quantity at a prespecified price) with processors, who can act as intermediaries for growers in their futures hedging activity. This paper seeks to explain why futures markets can promote share diversification even when growers and processors have symmetric access to futures markets.

The opportunity to hedge in a futures market changes the incentives for share diversification, because futures contracts do not serve equally well for hedging different types of risk. A grower who is endowed with the revenue distribution $\beta_{i} P q+P \epsilon_{i}$ can partly hedge his systematic revenue risk $\left(\beta_{i} P q\right)$ but cannot hedge his idiosyncratic risk $\left(P \epsilon_{i}\right)$ by using the futures market. The idiosyncratic risk $P \epsilon_{i}$ is unhedgeable because it is uncorrelated with the payoff on a futures contract $P-\phi$, where $\phi$ is the futures price. ${ }^{18}$

The point we seek to illustrate in this section is as follows. When share contracting increases the sum of the variances (including growers and the processor) of hedgeable risks above the sum of the hedgeable variances of the separate producers, futures trading encourages share contracting. This can easily occur, because shares large enough to adequately diversify idiosyncratic risk may be too large from the point of view of evenly spreading systematic risk.

In the next subsection, we describe optimal futures positions for a grower or processor, either with or without share contracting. This prepares us to examine the gains to share diversification when a futures market is available. We examine share purchases first from two and then from many growers in Section III.2 and Section III.3 respectively.

\footnotetext{
18 However, share contracts are not ideal for the purpose of intermediated futures hedging, as they provide the processor with an incentive to hedge only the share that he purchases. Futures hedging via processors could be effected more fully through fixed-quantity forward contracts, in which the grower sells forward an optimal quantity which the processor can then offset with a short position on the futures market.
} 


\section{I. Optimal Futures Positions}

Under mean-variance preferences, and taking share purchases as given, an individual's optimal futures hedge is independent of his idiosyncratic risk exposure, and is linear in his systematic risk, as described in the following Lemma.

Lemma I For a grower or processor with mean-variance preferences and output distribution net of share transaction of $q_{i}=b_{i} q+c_{i} \epsilon_{i}$, the optimal futures hedge is

$$
\xi_{i}=b_{i} \frac{\operatorname{cov}(P q, P)}{\operatorname{var}(P)}+\frac{\mathrm{E}(P)-\phi}{A \operatorname{var}(P)} .
$$

Proof: The consumption constraint is $C=W+b_{i} P q+c_{i} P \epsilon_{i}+\xi_{i}(P-\phi)$. Substituting for the mean and variance of $C$ in equation (3), the first order condition with respect to $\xi_{i}$ becomes

$$
\mathrm{o}=\frac{\mathrm{E}(P)-\phi}{A}-\xi_{i} \operatorname{var}(P)-c_{i} \operatorname{cov}\left(P \epsilon_{i}, P\right)+b_{i} \operatorname{cov}(P q, P) .
$$

As $\epsilon_{i}$ is conditionally independent of $P, \operatorname{cov}\left(P \epsilon_{i}, P\right)=\mathrm{o}$, so (9) obtains.

In Lemma I, for a grower or a processor who does not trade shares, we have $b_{i}=\beta_{i}, c_{i}=\mathrm{I}$, or $b_{i}=\mathrm{o}, c_{i}=\mathrm{o}$ respectively. For a grower or a processor who does trade shares, we have $b_{i}=(\mathrm{I}-s) \beta_{i}, \quad c_{i}=\mathrm{I}-s$ or $b_{i}=s \beta_{i}, \quad c_{i}=s$ respectively.

\section{III.2. Combining Two Shares with Futures Trading}

The ability to hedge on the futures market need not reduce the gain from share contracting described in Section II. Consider the total consumption inclusive of futures trading payoffs of a grower or processor who engages in share contracting,

$$
C_{i}=W+b_{i} Z^{\prime}+c_{i} w_{i}+\frac{\mathrm{E}(P)-\phi}{A \operatorname{var}(P)}(P-\phi),
$$

where $Z^{\prime} \equiv P q+[\operatorname{cov}(P q, P) / \operatorname{var}(P)](P-\phi)$. The three stochastic components of consumption, the hedged systematic risk $Z^{\prime}$, the idiosyncratic risk $w_{i}$, and the third term, which represents the payoff on the futures position taken to exploit bias, are uncorrelated, by the statistical properties of the output distribution described in Section I. Hence futures trading, while useful for hedging systematic risk, is still of no help in transferring the idiosyncratic components of output risk.

The conditions for profitable combination of shares when there is futures trading requires only a slight modification of that in Section II.2. The gain to share contracting is proportional to the reduction in the sum of variances of the transacting parties. As we do not consider the possible effect of share contracting on the distribution of aggregate output (and consequently on 
futures risk premia), within the framework of this paper, the third term in (Io) has no effect on the difference in total variance with and without shares, and is uncorrelated with any of the other terms. Furthermore, just as with $Z$, the hedged systematic risk $Z^{\prime}$ is uncorrelated with idiosyncratic risk $w_{i}$. Hence, the expression for the gains to share diversification has the same form as (7) with $Z$ replaced by $Z^{\prime}$. Intuitively, a processor who purchases revenue distribution $b_{i} P q+c_{i} P \epsilon_{i}$ will also acquire the futures position given by (9) to hedge his share purchase, so the effective systematic risk becomes $Z^{\prime}$. We therefore have

Proposition 3 Share Diversification with Futures

When a futures market exists, share diversification is profitable if and only if $(7)$ holds with $Z$ replaced by $Z^{\prime}$.

As each grower hedges to offset movements in $Z, \sigma_{Z^{\prime}}^{2}<\sigma_{Z}^{2}{ }^{19}$ It follows that

Corollary to Proposition 3 Complementarity of Futures with Shares Share contracting is more profitable with futures trading than without if and only if

$$
\left(\beta_{1}^{2}+\beta_{2}^{2}\right) s(\mathrm{I}-s)-\beta_{1} \beta_{2} s^{2}<0 .
$$

Proposition I of Section II showed that if the share purchase is high, then variability of common risk, $\sigma_{z}^{2}$, is a deterrent to combining risks. Proposition 3 and its Corollary imply that futures hedging, by reducing common risk, can increase the gain to growers and processors of share contracting. Within the context of our (partial equilibrium) analysis, the introduction of a futures market benefits growers and processors even without share contracting by improving risk sharing; but in addition, it can increase the incremental benefit to share contracting.

To interpret (I I) further, consider the case $\beta_{1}=\beta_{2}$, so that condition (I I) implies that $\beta^{2} s(2-3 s)<0$. This obtains so long as $s>2 / 3$. Hence, for a sufficiently large share purchase, futures trading promotes share contracting. Section II described how share diversification is deterred by high output sensitivities $\left(\beta_{i}\right)$ relative to idiosyncratic risk, if only large shares can be purchased. As futures contracts are useful to hedge against systematic but not unsystematic risk, futures trading reduces the cost of share diversification without sacrifice of the benefits in idiosyncratic risk reduction. ${ }^{20}$

\section{III.3. Combining Many Shares with Futures Trading}

The tendency of futures trading to be complementary with share contracting increases when the shares of several rather than just two growers can be combined. For a given size of the share purchase, multiple purchases involve

19 To see this, note from the definition of $Z^{\prime}$ that

$$
\operatorname{var}\left(Z^{\prime}\right)=\operatorname{var}(P q)-\frac{[\operatorname{cov}(P q, P)]^{2}}{\operatorname{var}(P)}<\operatorname{var}(P q)=\operatorname{var}(Z) .
$$

${ }^{20}$ Diamond ( 1984 ) showed how the use of futures can make financial intermediation more profitable. In his model the cost of delegated monitoring of managers is reduced by futures trading, even though all individuals are risk neutral. Here, the advantage to futures trading is in improved risk sharing.

(C) Royal Economic Society I 993 
loading more systematic risk on the processor. Thus, the benefit to being able to hedge this risk in the futures market increases.

If growers are identical and if futures trading is allowed, the gain from share diversification would be given by (8) above, with $Z$ replaced by $Z^{\prime}$, defined in (Iо). As $\sigma_{Z^{\prime}}^{2}<\sigma_{Z}^{2}$,

\section{Proposition 4 Many Growers with Futures}

Futures trading increases/decreases the gains to share diversification as $s \gtrless 2 /(m+\mathrm{I})$. Allen ( 1985 ) has provided a model in which, owing to adverse selection, the grower gives up a share of approximately I/2. Roy ( I 963 ) provides evidence that growers usually commit to deliver $50 \%$ of the output in share contracts for barley in the United States. The discussion by Byres ( 1983 ) indicates that in Italian sharecropping contracts, a share size of $2 / 3$ is common. When $s=\mathrm{I} / 2$ or $2 / 3$, futures trading promotes share diversification for $m>3$ and $m>2$ respectively. As commodity markets are usually organised with many small growers and relatively few large processors, this suggests that normally futures trading and share contracting will be complementary means of transferring risk.

If $m$ is large, then futures trading will promote share contracting even if shares are small, because the variance of systematic risk is a convex function of $\beta$. Purchasing more shares raises the processor's sensitivity to systematic output risk, so that the variance and acceptance premium rises disproportionately; when purchasing from many growers, the value to reducing this risk through the futures market increases.

The complementarity of futures and share contracting should be strongest for commodities with highly elastic or inelastic demand, as this preserves variability in $Z$. For near unitary elastic demand, output shocks tend to be offset closely by price, leading to little systematic revenue variability. For grains, however, inelastic demand is the norm.

A qualification to the analysis is that the presence or absence of a futures market may affect the size of share purchases, $s$. With the share purchase endogenous, the condition from Proposition $4, s^{*}>2 /(m+1)$, where $s^{*}$ is the optimal share purchase in the absence of a futures market, is sufficient for the complementarity of futures trading with share contracting. This condition is not necessary, however, since the gain to share contracting with futures is increased when the share size can be adjusted. In Section IV, we solve for the size of the optimal share purchases in the presence and absence of a futures market and develop a milder sufficient condition for futures to promote share contracting.

\section{THE OPTIMAL SHARE PURGHASE}

In the preceding sections, the size of the share purchases has been taken to be exogenous, as was the number of growers from whom the processor buys shares. In this section, these are both determined as part of a market equilibrium. We will see that futures and share contracting will typically be complementary even when the share size is endogenous. 


\section{IV.I. Optimal Shares without Futures Trading}

Let there be $N$ identical growers and $L$ identical processors, $N>L$. Each of the growers and processors is endowed with an initial wealth $W$. We assume that processors and growers behave competitively in their share transactions and that entry is prohibitively costly. We further assume that the revenues of all growers are identically distributed with common systematic risk parameter $\beta$, common idiosyncratic variance $\sigma^{2}$ and common covariance $\sigma_{i j}$ given by (2).

Let $X$ be the amount that a processor pays each grower from whom he purchases a share. We assume that transaction costs faced by processors engaging in share contracting have two components: a per-grower component $t_{1}$ and a fixed component $t_{0}{ }^{21}$ These costs are identical across processors. Let $m$ be the number of growers with whom one processor transacts. The processor maximises his expected utility subject to the constraint that each grower with whom he contracts achieves a reservation level of utility $U_{r}$ (also identical across growers) after transacting. We assume that each grower can achieve an 'autarky' level of expected utility $U_{a}$ without engaging in any share contracting. However, competition by processors might, in equilibrium, cause the growers' reservation utility $U_{r}$ to exceed $U_{a}$.

The choice variables for a processor are the number of growers contracted with $m$, the size of the share purchase $s$, and the side-payment $X$. Without loss of generality, $s$ and $X$ are assumed to be identical across the identical growers. By (2), the processor's problem is

$$
\max _{m, s, X} s m \beta \mathrm{E}(Z)+W-t_{0}-m\left(X+t_{1}\right)-\frac{A}{2}\left[s^{2} m^{2} \beta^{2} \sigma_{Z}^{2}+\left(m-\frac{m^{2}-m}{N-\mathrm{I}}\right) \sigma^{2} s^{2}\right]
$$

$$
\text { subject to } W+(\mathrm{I}-s) \beta \mathrm{E}(Z)+X-\frac{A}{2}\left[(\mathrm{I}-s)^{2}\left(\beta^{2} \sigma_{Z}^{2}+\sigma^{2}\right)\right]=U_{r} \text {. }
$$

Let $m^{*}$ and $s^{*}$ be the locally optimal values of $m$ and $s$ obtained from the system of first order conditions with respect to $m, s$, and $X$ and subject to the constraint (I3) arising from the above problem. We will say that a processor 'profits' from share contracting if his expected utility from share contracting in (I2) exceeds his autarky utility of $W$. If the fixed transaction cost $t_{0}$ is sufficiently high, the locally optimal $m^{*}$ and $s^{*}$ will yield negative profits. Hence, the global optimum is either $m=0$ if this occurs, or else is $m^{*}, s^{*}$. Thus, the nature of the equilibrium depends on the levels of the two transaction cost components $t_{0}$ and $t_{1}$.

We begin our analysis of the maximisation problem (I 2) by solving for the (locally) optimal share purchase $s^{*}$ given that $m=m^{*}$. Substituting for $X$ from (13) into (I2) and setting the partial derivative with respect to $s$ of the resulting

${ }^{21}$ The fixed component $t_{0}$ may be viewed as a cost of learning about the determinants of output. Goldsmith (1985) suggests several factors that a processor must investigate, including the climate, the growers' experience, and the desirability of alternative techniques employed.

(C) Royal Economic Society 1993 
expression to zero, we obtain an expression for $s^{*}$ (assuming any share transaction is profitable):

$$
s^{*}=\frac{\beta^{2} \sigma_{Z}^{2}+\sigma^{2}}{\left(\mathrm{I}+m^{*}\right) \beta^{2} \sigma_{Z}^{2}+\gamma^{*} \sigma^{2}}, \quad \text { where } \quad \gamma^{*} \equiv \frac{2 N-m^{*}-\mathrm{I}}{N-\mathrm{I}} .
$$

Since $\gamma^{*}>\mathrm{I}, \mathrm{o}<s^{*}<\mathrm{I}$.

The value of $t_{0}$ does not influence the locally optimal $m^{*}, s^{*}$. On the other hand, $m^{*}$ is a decreasing function of $t_{1}$ and of $U_{r}$, as is evident after substituting for $X$ from (13) into (12). Three classes of equilibria that arise are described in the Appendix. In brief, these cases are: (I) No share contracting takes place (the $\operatorname{cost}^{-} t_{1}$ is too large), (2) some but not all growers engage in share contracting ( $t_{1}$ falls in an intermediate range), and (3) all growers engage in share contracting $\left(t_{1}\right.$ is sufficiently low). In both Cases 2 and 3 , if share contracting is profitable, then substituting the equilibrium $m^{*}$ into (I4) gives the equilibrium share purchase $s^{*}$.

\section{IV.2. Optimal Shares with Futures Trading}

Let $m^{*}$ as before refer to the optimal number of growers contracted with in the absence of futures trading, given that share contracting takes place. The (locally) optimal $m^{*}$ is the solution to a quadratic equation (provided in the Appendix) with rather complicated coefficients. For simplicity we initially constrain $m=m^{*}$ and $U_{r}$ to be unchanged with the introduction of futures. This provides a lower bound to the increased benefit of share contracting brought about by futures trading. We then provide a numerical example which shows that the ability to vary $m$ can dramatically increase the gains to share contracting when a futures contract is introduced.

Given the above constraints, the optimal share $S^{*}$ is given by (I4), with $\sigma_{Z}^{2}$ replaced by $\sigma_{Z^{\prime}}^{2}$. Hence, by (8) and the discussion following Lemma I, futures trading encourages share diversification if

$$
\begin{aligned}
m^{*} \beta^{2} \sigma_{Z}^{2} s^{*}[ & {\left[2-\left(m^{*}+\mathrm{I}\right) s^{*}\right]+\left(2 s^{*}-\gamma^{*} s^{* 2}\right) m^{*} \sigma^{2} } \\
& <m^{*} \beta^{2} \sigma_{Z^{\prime}}^{2} S^{*}\left[2-\left(m^{*}+\mathrm{I}\right) S^{*}\right]+\left(2 S^{*}-\gamma^{*} S^{* 2}\right) m^{*} \sigma^{2} .
\end{aligned}
$$

Substituting for $s^{*}$ and $S^{*}$ in (I 5 ) and cancelling the common factor $m^{*}$ gives

Proposition 5 Complementarity with Endogenous Share Purchase A sufficient condition for futures trading to promote share diversification is

$$
\frac{\left(\beta^{2} \sigma_{Z}^{2}+\sigma^{2}\right)^{2}}{\left(m^{*}+\mathrm{I}\right) \beta^{2} \sigma_{Z}^{2}+\gamma^{*} \sigma^{2}}<\frac{\left(\beta^{2} \sigma_{Z^{\prime}}^{2}+\sigma^{2}\right)^{2}}{\left(m^{*}+\mathrm{I}\right) \beta^{2} \sigma_{Z^{\prime}}^{2}+\gamma^{*} \sigma^{2}} .
$$

As was noted in the previous section, in the absence of a futures market, with a sufficiently high $t_{0}$ share contracting could be entirely deterred because processors could earn negative profits from share contracting at the local optimum $m=m^{*}$. However, with the introduction of the futures market, if ( 16 ) holds, the processor could profit at $m=m^{*}$. In such a case, the introduction of futures leads to greater share contracting between growers and processors. We 
now provide a numerical example which illustrates the gains to share contracting when $m$ is allowed to vary.

\section{Numerical Illustration}

Let $\beta=\mathrm{I}, \sigma^{2} / \sigma_{Z}^{2}=5, \sigma=\$ 20,000, \mathrm{E}(Z)-\left(t_{1}+U_{r}-W\right)=\$ 50,000, t_{0}=\mathrm{o}$, $\sigma_{Z}^{2} / \sigma_{Z^{\prime}}^{2}=2, A=\mathrm{I} / 4,000$, and $N=50^{22}$ The optimal number of growers in the absence of futures is then Io, while in the presence of futures, the number increases to 37 . Using these values, evaluating the left-hand side of (15) and multiplying by $A / 2$ we obtain the reduction in total risk premium per processor (alternatively, the increase in total social surplus) from share contracting in the absence of futures trading to be $\$ \mathrm{I} 79,268$. The reduction in risk premium with futures trading allowed (the right-hand side of (I5)) is $\$ 44 \mathrm{I}, 927$. Thus, some not unreasonable parameter values suggest that the increase in total surplus due to share contracting is at least $\$ 262,659$ greater in the presence of a futures market than in its absence.

The numerical example provides a case in which the introduction of futures increases the extent of share contracting substantially. In general, one may expect the degree of complementarity between futures and shares to depend on the hedging effectiveness of the particular futures contract (measured by $\left.\sigma_{Z^{\prime}}^{2} / \sigma_{Z}^{2}\right)$, which, in turn, depends on the correlation between grower revenue and the spot price. This correlation may be quite low, for example, in the case of multinational processors who share contract with growers belonging to small countries without developed futures markets. In such a case, the extent of complementarity will be lower than that suggested by our example.

An implication of the analysis is that one may expect share contracting to become more widespread following the introduction of futures. One can also identify which growers are more likely to enter share contracts after introduction of a futures market. In the absence of futures trading, share contracting will tend disproportionately to involve growers with unusual output distributions, e.g. with low or negative sensitivities to systematic factors. Combining low-sensitivity distributions (or negative-sensitivity distributions with positive-sensitivity distributions) takes greatest advantage of idiosyncratic risk diversification while minimising the concentration of (or even diversifying) systematic risk. Examples are growers who farm on deviant locations (e.g. hill vs. valley) or use deviant technologies (e.g. fertilisers or pesticides that offer differing protection across states of nature). This phenomenon is predicted to be strongest in commodities with highly elastic or

${ }^{22}$ The other estimates were derived as follows. By (I), the typical value for $\beta$ is unity. The value for $\sigma^{2} / \sigma_{z}^{2}$ is roughly consistent with the regressions of county on national output of Johnson (1945) and Salmon (1985). The values for $\sigma, \mathrm{E}(Z)-\left(t_{1}+U_{r}-W\right)$, and $N$ are scale assumptions and are not crucial for the illustration. Grant (1985) estimates the range for the proportion of total revenue variance eliminated by futures hedging for individual states to be roughly $15-40 \%$. Futures hedging would reduce total risk by less for counties than for states because, in general, states have more diversified idiosyncratic risk. As our numbers correspond to the county level, we select a value for $\sigma_{Z}^{2} / \sigma_{z}^{2}$, implying a total revenue risk reduction of about $9 \%$, a fairly conservative assumption. Estimates of the coefficient of relative risk aversion ranging from 2 to 16 have been obtained by a number of capital market studies. We use io as an intermediate value of the coefficient of relative risk aversion and scale it down by a wealth level of $\$ 40,000$ to estimate the coefficient of absolute risk aversion. 
inelastic demand, as revenues from such commodities would be particularly sensitive to systematic influences. Our analysis suggests that the introduction of futures weakens the tendency for processors to limit their contract with such growers, so, following the introduction of futures, one expects to see a broader representation of growers in the pool with which processors share contract.

\section{Differing Risk Aversion of Growers and Processors}

We now show that the complementarity of futures with shares obtains even if the processor is more risk tolerant than the growers, as might be expected if growers are more closely held. As a processor becomes more risk tolerant he accumulates more systematic risk, but becomes less distressed by any given magnitude of risk. In the limit, as processors become risk neutral, the advantage of being able to hedge must reverse and decline to zero, because processors can costlessly bear all risk even without the futures market. Despite this, we show by example that a reduction in the risk aversion of the processor, the risk preference of growers held constant, can still raise the complementarity of futures with shares.

Let us scale the risk aversion parameter $A$ of the processor down by a factor $Q<\mathrm{I}$. The share purchase becomes

$$
s^{*}=\frac{\beta^{2} \sigma_{Z}^{2}+\sigma^{2}}{\left(\mathrm{I}+Q m^{*}\right) \beta^{2} \sigma_{z}^{2}+\gamma^{*} \sigma^{2}}, \quad \text { where } \quad \gamma^{*} \equiv \frac{(Q+\mathrm{I}) N-Q m^{*}-\mathrm{I}}{N-\mathrm{I}}
$$

and the modified form of condition (I6) is

$$
\frac{\left(\beta^{2} \sigma_{Z}^{2}+\sigma^{2}\right)^{2}}{\left(Q m^{*}+\mathrm{I}\right) \beta^{2} \sigma_{Z}^{2}+\gamma^{*} \sigma^{2}}<\frac{\left(\beta^{2} \sigma_{Z^{\prime}}^{2}+\sigma^{2}\right)^{2}}{\left(Q m^{*}+\mathrm{I}\right) \beta^{2} \sigma_{Z^{\prime}}^{2}+\gamma^{*} \sigma^{2}} .
$$

If $Q=0 \cdot 8$, using the same numbers as earlier, the optimal number of growers with whom the processor contracts increases from 12 to 46 when a futures contract is introduced. The net gains from share contracting are $\$ 230,990$ and $\$ 574,370$, with and without futures trading respectively. The advantage of futures trading is therefore at least $\$ 343,380$, which is higher than in the previous illustration in which $Q=\mathrm{I}$. The above result can be formalised by a proposition.

\section{Proposition 6 Differing Risk Aversion of Growers and Processors}

There exist exogenous parameter values under which the complementarity of futures with share contracting is strengthened when the risk aversion of the processor is reduced from a starting point at which growers and processors are equally risk averse.

\section{GONGLUSION}

A processor who purchases crop shares at a pre-specified price from multiple growers can pool idiosyncratic output risk. When the contemplated share purchases are large, the unhedged systematic (common) components of output risk act to deter extensive risk-pooling. As futures payoffs are uncorrelated with idiosyncratic risks and highly correlated with market-wide output variability, 
futures markets can be used to transfer the common component of revenue variability to outside speculators without reducing the benefit from diversifying idiosyncratic risk. Therefore, futures trading will usually be complementary with share contracting. These results contrast with the initially appealing view that alternative methods of risk reduction are substitutes. For example, McCloskey and Nash (1984) point out that the option to carry a crop over to the next season is a protection against low price. They maintain that declines in storage costs from medieval to modern times led to the transition from scattered strip farming (which diversifies output risks) to integrated plots of land.

Stiglitz (1974) suggested that sharecropping (as distinct from share contracting with a processor) was discouraged by the development of modern risk-sharing markets because 'landlords and workers (to the extent that they had capital), could diversify their portfolio [which] meant that the relative importance of sharecropping as a risk sharing arrangement declined'. Modern capital markets have reduced the cost of equity issuance, which would indeed substitute for sharecropping. The reduced cost of equity issuance may also help to explain why sharecropping is more prevalent in less-developed countries (LDC's), which tend to have less-developed equity markets. At the same time, the existence of equity markets makes the prevalence of (non-rental forms of) share contracting in advanced economies more puzzling. Our analysis implies that, insofar as futures contracts are complementary with share contracting, the active futures markets available in developed countries may have helped maintain the viability of share contracting. ${ }^{23}$ Furthermore, an empirical implication of our analysis is that the introduction of futures in LDC's would enhance the extent of sharecropping in such countries because of the complementarity of futures with share contracting and sharecropping.

Our model may also help to explain why we do not observe contracts depending on aggregate as well as individual output that might appear to be desirable from a risk-sharing point of view. A processor could, for example, write a contract with several growers agreeing to purchase the idiosyncratic components of their outputs, which could be extracted since aggregate output is observable. This would pool idiosyncratic risks without loading large amounts of systematic risk onto the processor. When a futures market is present, the benefits of this arrangement can largely be obtained by combining two more familiar contracts: share purchases by a processor who then sloughs off part of his systematic risk on the futures market.

University of California, Los Angeles

Columbia University

Date of receipt of final typescript: July 1992

23 It seems likely that share contracting is associated with less informational asymmetry than either publicly held equity or sharecropping. Thus, equity issuance to uninformed investors may be a better substitute for sharecropping arrangements with uninformed landlords than for share contracting with a relatively well-informed processor.

(C) Royal Economic Society I 993 


\section{REFERENCES}

Allen, F. (i 985 ). 'On the fixed nature of sharecropping contracts.' Economic Journal, vol. 95, pp. 30-48.

Braverman, A. and Stiglitz, J. (I986). 'Cost-sharing arrangements under sharecropping: moral hazard, incentive flexibility, and risk.' American Journal of Agricultural Economics, vol. 68, pp. 642-52.

Byres, T. J. ( 1983 ). 'Historical perspectives on sharecropping.' In Sharecropping and Sharecroppers (ed. T. J. Byres). London: Frank Cass.

Cheung, S. (1983). The Theory of Share Tenancy. Chicago: University of Chicago Press.

Diamond, D. and Verrecchia, R. (I982). 'Optimal managerial contracts and equilibrium security prices.' Journal of Finance, vol. 37 , pp. $275^{-87}$.

Diamond, D. ( 1984 ). 'Financial intermediation and delegated monitoring.' Review of Economic Studies, vol. 5I, pp. 393-4I4.

Glover, D. (1987). 'Increasing the benefits to smallholders from contract farming: problems for farmers' organizations and policy makers.' World Development, vol. I 5, pp. $44 \mathrm{I}-8$.

Goldsmith, A. (1985). 'The private sector and rural development: can agribusiness help the small farmer?' World Development, vol. I3, pp. I I $25-38$.

Grant, D. (I 985 ). 'Optimal futures positions for producers who face price and yield risk', unpublished manuscript, University of New Mexico, Albuquerque.

Hart, O. and Holmström, B. ( I 987). 'The theory of contracts.' In Advances in Economic Theory (ed. T. Bewley), pp. 7I-I55. Cambridge: Cambridge University Press.

Hirshleifer, D. (I 988 ). 'Risk, futures pricing and the organization of production in commodity markets.' Journal of Political Economy, vol. 96, pp. 1 206-20.

Johnson, D. (i 945$)$. 'A price policy for agriculture.' Journal of Farm Economics, vol. 27, pp. 76 I-72.

Kimball, M. S. ( I 988). 'Farmers' cooperatives as behaviour towards risk.' American Economic Review, vol. 78, pp. 224-32.

Lippman, S. and Mamer, J. (I988). 'When many wrongs make a right: an asymptotic analysis of risk aversion and additive risks.' Probability in Engineering and Informational Sciences, pp. I I 5-27.

McCloskey, D. (1976). 'English open fields as behavior toward risk.' Research in Economic History, vol. I, pp. I $24-70$.

McCloskey, D. and Nash, J. (I984). 'Corn at interest: the extent and cost of grain storage in medieval England.' American Economic Review, vol. 74, pp. I 74-87.

Miller, S. (1986). 'Forward cash contracting of cotton.' Journal of Futures Markets, vol. 6, pp. 249-59.

Newbery, D. ( I 976$)$. 'Risk sharing, sharecropping and uncertain labour markets.' Review of Economic Studies, vol. 44 , pp. 585-94.

Newbery, D. (1983). 'The state of leasing theory: conflicts among different models of decision making under uncertainty.' In Rents and Rental Practices in U.S. Agriculture: Proceedings of a Workshop on Agricultural Rents (ed. J. Debraal and G. Wunderlich). The Farm Foundation in Cooperation with Economic Research Service, U.S. Department of Agriculture.

Newbery, D. (1987). 'On the accuracy of the mean-variance approximation for futures markets.' Mimeographed, University of California, Berkeley.

Newbery, D. and Stiglitz, J. (1979). 'Sharecropping, risk sharing, and the importance of imperfect information.' In Risk, Uncertainty and Agricultural Development (ed. J. Roumasset and J. Boussard). New York: Agricultural Development Council.

Newbery, D. and Stiglitz, J. (198I). The Theory of Commodity Price Stabilization. Oxford: Clarendon Press.

Paul, A., Heifner, R. and Helmuth, J. (I976). 'Farmers' use of forward contracts and futures markets.' Agricultural Economic Report No. 320, United States Department of Agriculture, Economic Research Service.

Pratt, J. and Zeckhauser, R. (1987). 'Proper risk aversion.' Econometrica, vol. 55, pp. I43-54.

Ross, S. (1978). 'Mutual fund separation in financial theory - the separating distributions.' Journal of Economic Theory, vol. I 7, pp. 254-86.

Roy, E. P. ( 1963$)$. 'Contract farming U.S.A.' Danville, Illinois: Interstate Printers and Publishers.

Salmon, J. ( 1985 ). 'The emergence of organized futures markets and the distribution of consumption risk.' PhD Dissertation, University of California, Los Angeles.

Samuelson, P. (1 963). 'Risk and uncertainty: a fallacy of larger numbers.' Scientia, vol. 98, pp. i o8-13.

Stiglitz, J. (1974). 'Incentives and risk sharing in sharecropping.' Review of Economic Studies, vol. 4I, pp. 2 I $9-55$.

United States Department of Agriculture, Economic Research Service (1977). 'The U.S. grain trade in I974.' Agricultural Economic Report No. 386.

Weller, P. and Yano, M. (1992). 'An introduction to the theory of hedging and speculation in futures markets.' Chapter I in Theory of Futures Markets (ed. Paul Weller), pp. I5-35. Oxford: Blackwell. 


\section{APPENDIX}

This Appendix first describes in detail the various types of equilibria that arise from an analysis of the maximisation problem represented by (12) and (I3) in Section IV.I and then presents the quadratic equation which provides the locally optimal value of $m$, the number of growers with whom the processor contracts.

\section{Classes of Equilibria}

Case $I: t_{1} \geqslant \bar{t}_{1}$, where $\bar{t}_{1}$ is the minimum value such that if $t_{1} \geqslant \bar{t}_{1}$, even if $U_{r}$ is at its minimum value $U_{a}$ (the growers' autarky level), there is no local optimum with $m^{*}>$ o, i.e. share contracting is entirely deterred in equilibrium.

Case 2: $t_{1}^{c}<t_{1}<\bar{t}_{1}$, where $t_{1}^{c}$ is a lower critical value for $t_{1}$ such that if $U_{r}=U_{a}$ and $t_{1}=t_{1}^{c}$, then $m^{*}=N / L$, the market-wide ratio of growers to processors. If $t_{1}^{c}<t_{1}<\bar{t}_{1}$, then, at the local optimum each processor contracts with a positive number of growers $m^{*}$, such that $\mathrm{o}<m^{*} \leqslant N / L$. If $t_{0}$ is sufficiently low as to yield non-negative profits at $m^{*}, m^{*}$ will be the globally optimal equilibrium value of $m$. However, some left-over growers in equilibrium will be unable to contract with any processor. This surplus of growers is consistent with an equilibrium reservation utility equal to the autarky level $U_{a}$. On the other hand, if $t_{0}$ is too high, then, as in Case $\mathrm{I}$, no share contracting takes place in equilibrium.

Case $3: t_{1} \leqslant t_{1}^{c}$. If $U_{r}$ were equal to $U_{a}$, then $m^{*}$ would be greater than $N / L$. This cannot be an equilibrium, as it constitutes an excess demand by processors for growers with whom they can contract. As with Case 2, if $t_{0}$ is sufficiently large, no share contracting takes place in equilibrium. Assuming $t_{0}$ is sufficiently low, competition among processors causes $U_{r}$ to be forced up through increases in the side-payment $X$, choking back the size of $m^{*}$. We distinguish two subcases depending on the level of $t_{0}$.

- If $t_{0}$ is below a critical level $t_{0}^{c}$, processors earn non-negative profits at $m^{*}=N / L$, which is the equilibrium.

- If $t_{0} \geqslant t_{0}^{c}$, processors would earn negative profits if $U_{r}$ were sufficiently high as to reduce the local optimum to $m^{*}=N / L$. Hence, in equilibrium some processors will contract with growers, some processors will not engage in any contracting arrangements with growers, and all processors will earn zero profits. The equilibrium $U_{r}$ is the value that implies zero profits to a processor maximising (I2) subject to (13). The equilibrium $m^{*}$ arises as the solution to this problem given $U_{r}$. $\hat{L}$, the number of processors who purchase shares, must satisfy the equilibrium condition $\hat{L}=N / m^{*}{ }^{24}$

\section{The optimal number of growers, $m^{*}$}

Substituting for $X$ from (13) into (12), setting the partial derivative with respect to $m$ to zero, and substituting for the share purchase from ( 14 ), it follows that in the absence of futures, $m$ solves the quadratic equation

$$
a m^{2}+b m+c=0,
$$

24 If $N / L$ or $N / \hat{L}$ are not integers, then in equilibrium there may be a processor who either sits out or contracts with fewer growers than do the other processors. We rule out such discreteness problems for brevity in the above subcases.

(C) Royal Economic Society 1993 
where

$$
\begin{aligned}
a= & A\left(\beta^{2} \sigma_{Z}^{2}+\sigma^{2}\right)\left[\beta^{4} \sigma_{Z}^{4}(N-\mathrm{I})^{2}-2 \beta^{2} \sigma^{2} \sigma_{Z}^{2}(N-\mathrm{I})+\sigma^{4}\right] \\
& -2\left[\mathrm{E}(Z)-\left(t_{1}+U_{r}-W\right)\right]\left[\beta^{2} \sigma_{Z}^{2}(N-\mathrm{I})-\sigma^{2}\right]^{2} \\
b= & 2 A\left(\beta^{2} \sigma_{Z}^{2}+\sigma^{2}\right)\left[\left(\beta^{4} \sigma_{Z}^{4}+2 \beta^{2} \sigma^{2} \sigma_{Z}^{2}\right)(N-\mathrm{I})^{2}-\sigma^{4}(2 N-\mathrm{I})\right] \\
& -4\left[\mathrm{E}(Z)-\left(t_{1}+U_{r}-W\right)\right]\left[\beta^{2} \sigma_{Z}^{2}(N-\mathrm{I})-\sigma^{2}\right]\left[\beta^{2} \sigma_{Z}^{2}(N-\mathrm{I})+\sigma^{2}(2 N-\mathrm{I})\right] \\
c= & A N \sigma^{2}\left(\beta^{2} \sigma_{Z}^{2}+\sigma^{2}\right)\left[\beta^{2} \sigma_{Z}^{2}(N-\mathrm{I})+\sigma^{2}(2 N-\mathrm{I})\right] \\
& -2\left[\mathrm{E}(Z)-\left(t_{1}+U_{r}-W\right)\right]\left[\beta^{4} \sigma_{Z}^{4}(N-\mathrm{I})^{2}+2 \beta^{2} \sigma^{2} \sigma_{Z}^{2}(N-\mathrm{I})(2 N-\mathrm{I})+\sigma^{4}(2 N-\mathrm{I})^{2}\right] .
\end{aligned}
$$

With futures, the optimal number of growers is obtained by solving the same quadratic equation, while replacing $\sigma_{z}^{2}$ by $\sigma_{z}^{2}$, in the expressions for the coefficients $a, b$, and $c$. For the parameter values in the numerical illustration, the quadratic equation has a unique positive root. 